\title{
Time Series Dynamics of Short Term Interest Rates in Turkey
}

\author{
Emel Siklar \\ Anadolu University, FEAS, Department of Statistics \\ Yunus Emre Campus 26470 Eskisehir, Turkey \\ E-mail: esiklar@anadolu.edu.tr \\ Ilyas Siklar (Corresponding author) \\ Anadolu University, FEAS, Department of Economics \\ Yunus Emre Campus 26470 Eskisehir, Turkey \\ E-mail: isiklar@anadolu.edu.tr
}

Received: January 22, 2021 Accepted: February 17, $2021 \quad$ Published: March 4, 2021

doi:10.5296/ber.v11i1.18229 URL: https://doi.org/10.5296/ber.v11i1.18229

\begin{abstract}
Interest rate functions as the cornerstone for the heavy majority of the financial models. The high volatility in interest rates in the financial crisis of 2008/09 and resulting increased uncertainty led many researchers to focus on modeling the dynamics of changes in short term interest rates. This study aims to analyze the volatility of short-term interest rate in Turkey in terms of overnight repo rate and to forecast this rate for the next six months by modelling this volatility. For this purpose, the ARCH family models like ARCH, GARCH and EGARCH were preferred to use since they are the most common methods in the literature. Using the weekly frequency data for the period of January 2002 - January 2021, the model that best describes the stochastic volatility in the data was found to be the GARCH (1.1) model. As a result of the fact that the in-sample estimates were found sufficient, the interest rate estimates for the next 6 months were realized.
\end{abstract}

Keywords: Volatility, GARCH, EGARCH, Turkey

\section{Introduction}

In 2008 global economic turmoil, interest rates have shown substantial fluctuations in terms of both in their levels and volatility. In order to increase the return of their portfolio, 
fixed-income portfolio managers had to spend most of their time to solve the problems that were caused by the sort-term interest rate volatility. This process has shown that investors should be more informed in order to reduce the interest rate risk in bond portfolios. As a result, the importance of interest rate volatility in financial market analysis is better understood by investors (Brousseau \& Durre, 2013). As stated by Ariff \& Sarkar (2002), interest rate variability is important not only for the return of the portfolio but also for the proper investment decision. On the other hand, since monetary policy is carried out by using short-term interest rates that determine long-term interest rates, it is extremely important for central banks to examine short-term interest rate variability (Brousseau \& Durre, 2013).

The interest rate can traditionally be defined as the cost of borrowed funds. In this case, the interest rate is a concept that explains the transfer of savings from units with surplus of funds to those with fund deficit. Therefore, the interest rate has an important role both in terms of capital markets and money markets (van der Merwe et al, 2014). For the economy in general, the interest rate becomes the element that ensures the investment - savings equilibrium. On the other hand, according to Bean (2016), the interest rate is either the payment obtained for the unspent income or the cost of consumption in case of insufficient resources. Regardless of the point of view, due to the above definitions, interest rate forms the cornerstone of many financial models (Olweny, 2011). For example, the term structure of interest rates explains the link between short and long term rates. The divergence between them is important for determining future economic activities. On the other hand, short-term interest rates affect the change in long-term interest rates. For short, these links between short and long term interest rates settle the slope of the yield curve. It allows us to obtain clues on issues such as the course of future economic activities and market expectations (Bauer \& Mertans, 2018).

Short-term interest rate changes occur in response to developments in the economy in terms of both domestically and internationally such as local or international economic and political crises, changes in central bank policy rate, inflation, and expectations for economic growth (Joslin \& Konchitchki, 2018). On the other hand, it is widely accepted that changes in short-term interest rates also have an impact other macroeconomic variables such as economic growth, unemployment and balance of payments.

During the expansion period of the economy, the increase in short-term rates causes a rise in long-term rates considering the procyclical nature of interest rates; but, this rise is lower than the increase in short term rates (Dube \& Zhou, 2013). During the recession periods of the economy, the fluctuation in interest rates is greater. For example, there was a high volatility in interest rates in the financial crisis of 2008/2009, leading to increased uncertainty in the markets. Rising lack of confidence has led many researchers (for example, Chiarella et al., 2015; Olweny, 2011, Hegerty, 2014; Maranga et al., 2018) to focus on studying and modeling the dynamics of change in short-term interest rates. These academic works show that short-term interest rate affects the long-term interest rate and thus the return of bonds. Actions of monetary authorities in conducting monetary policy largely influence short term interest rate. For this reason, foreseeing changes in short-term interest rates is extremely substantial for bond holders since these changes affect the value of their bond portfolio. 
In this study, the volatility in short-term interest rates in Turkey will be examined in the context of repo rate and will be forecasted for the next 6-month period. The study consists of 4 chapters for this purpose. In the first part, the sources of variability in short-term interest rates are discussed and the recent empirical literature on this topic is summarized. The second section is related to the methodology that gives general information about the time series models to be applied in this study. In the third part of the study, data analysis is performed and the estimation results are discussed. In the fourth part, the results of the out of sample forecasts are evaluated. The conclusion section highlights the main results of the study.

\section{Short Term Interest Rate Volatility}

Volatility calibrates the variation in interest rates relative to the anticipated average interest rate (Sundaresan, 2009). As long as we calculate risk as a deviation from expected return, the volatility in interest rates is intended to explain the indeterminacy that causes high risk in money markets. According to Dabale \& Jagero (2013), in an economy, the prolonged rise in interest rates gradually lowers the return of real investments and accelerates buying and selling in financial instruments. Hegerty (2014) presents empirical proof indicating that interest rate volatility has an impact on the decisions of the government, investors, pension funds and individuals. Therefore, a large set of financial, political and global factors determines the movements in short-term interest rates.

A number of features can be mentioned regarding interest rate volatility: (1) It is stochastic in nature. (2) It includes uncovered elements and (3) It presents correlation with interest rate changes (Maranga et al., 2018). Studies examining the last feature identify a positive relationship (for example, Olan \& Sandy, 2005 and Olweny, 2011). This result is extremely important as it allows central banks to take action before the market (Brousseau \& Durre, 2013). On the other hand, considering the fact that short-term rates are more volatile than long-term rates, the issue becomes important in terms of risk management. Therefore, two points should be emphasized. First, a satisfactory model should include volatility when the term structure of interest rates is to be predicted. Second, volatility significantly affects the pricing and hedging interest rate derivatives.

The estimation of interest rate volatility is the determination of the uncertainty covering the expectations of the market (especially related to the future course of monetary policy rates). Analysis of interest rate volatility is vital for a central bank because its policy conducting largely includes raising or lowering the short-term interest rate. Decisions on this regard help to form market expectations regarding the future value of short-term interest rates (Brousseau $\&$ Durre, 2013).

Table 1 summarizes the results of recent studies on the method used, the country they are related to, and the best estimator. As can be seen from the table, the most commonly used techniques in volatility estimation are those related to the $\mathrm{ARCH}$ family. Therefore, in this study, modeling of the volatility of short-term interest rate in Turkey will be carried out through methods belonging to this family like ARCH, GARCH, EGARCH. 
Table 1. Summary of Recent Empirical Literature

\begin{tabular}{|l|l|l|l|}
\hline Paper & Methodologies Studied & Country & Suggested Model \\
\hline Boscher (2000) & $\begin{array}{l}\text { GARCH } \\
\text { Stochastic }\end{array}$ & $\begin{array}{l}\text { Japan, Germany, } \\
\text { England }\end{array}$ & Markov Switching \\
\hline Bali (2000) & ARCH Family & U.S.A. & GARCH \\
\hline Smith (2002) & $\begin{array}{l}\text { Markov Switching } \\
\text { Stochastic }\end{array}$ & U.S.A. & Stochastic \\
\hline Edwards\&Susmel(2003) & $\begin{array}{l}\text { Stochastic } \\
\text { GARCH }\end{array}$ & $\begin{array}{l}\text { Latin American } \\
\text { and Asian Countries }\end{array}$ & Stochastic \\
\hline Christiansen (2005) & ARCH Family & U.S.A. & GARCH \\
\hline Bali et al. (2006) & $\begin{array}{l}\text { Drift Functions } \\
\text { GARCH }\end{array}$ & U.S.A. & $\begin{array}{l}\text { Nonlinear Dirft } \\
\text { Function }\end{array}$ \\
\hline Floros (2008) & ARCH Family & Egypt & GARCH \\
\hline Leon (2008) & ARCH Family & Korea & GARCH \\
\hline Irfan et al. (2010a) & ARCH Family & Pakistan & GARCH \\
\hline Irfan et al. (2010b) & ARCH Family & Pakistan & GARCH \\
\hline Hong et al. (2010) & $\begin{array}{l}\text { Markov Switching } \\
\text { GARCH } \\
\text { Jump Diffusion }\end{array}$ & China & GARCH \\
\hline Diaz et al. (2010) & $\begin{array}{l}\text { Principal Components } \\
\text { EGARCH }\end{array}$ & Spain & Principle Component \\
\hline Olweny (2011) & ARCH Family & Kenya & GARCH \\
\hline Hou \& Suardi (2011) & Semi parametric & U.S.A. & Semi parametric \\
\hline Neupane (2011) & ARCH Family & Nepal & GARCH \\
\hline Hegerty (2011) & ARCH Family & Emerging European Countries & GARCH \\
\hline Koutmos (2012) & Extended EGARCH & U.S.A. & EGARCH \\
\hline Dayioglu (2012) & ARCH Family & U.S.A., Turkey & Assymetric GARCH \\
\hline Hegerty (2014) & ARCH Family & Latin American Countries & GARCH \\
\hline Tian \& Hamori (2015) & ARCH Family & Japan & Realized GARCH \\
\hline Takamizawa (2015) & $\begin{array}{l}\text { Level Dependent } \\
\text { Models } \\
\text { GEV }\end{array}$ & U.S.A & $\begin{array}{l}\text { Level Dependent } \\
\text { Godels }\end{array}$ \\
\hline Maik \& Nishat (2017) & Markov Switching & Pakistan & Markov Switching \\
\hline Hong et al. (2018) & ARCH Family & U.S.A. & GARCH \\
\hline Bayraci \& Unal (2018) & $\begin{array}{l}\text { Continuous Time } \\
\text { GARCH }\end{array}$ & Turkey & GARCH \\
\hline Li et al. (2019) & ARCH Family & Pakistan & GARCH \\
\hline Hassani et al. (2019) & ARCH Family & England & \\
\hline & & & \\
\hline
\end{tabular}

\section{Methodology}

Interest rate volatility is a key variable in many models used in financial markets. Therefore, estimating the volatility in financial time series is of great importance for both investors and government authorities. The use of standard deviation or variance in measuring volatility is one of the first phenomena taught in finance textbooks. Since the volatility of the returns has varying variances, the resulting fluctuations can create a pile. These aggregates are called the volatility cluster. The volatility of financial assets' returns includes heteroscedasticity which prevents the use of traditional estimation methods based on constant variance assumption. Autogressive conditional heteroscedasticity $(\mathrm{ARCH})$ model was developed for the first time 


\section{Macrothink}

by Engle (1982) for modeling the returns of financial assets. The purpose of this methodology is to model the conditionally changing variance by using past period values (Engle, 2001). While the ARCH process keeps the unconditional variance constant, it allows the conditional variance to change over time depending on the past error terms. Thus, the model can reveal the volatility clustering trend in the financial series. If we use $\left\{r_{t}\right\}$ to show the rate of return with its name in time series modelling, $\xi_{t}$ to represent the Gaussian white noise error term with zero mean and unit variance and $I_{t}=\left\{r_{1}, r_{2}, \ldots, r_{t-1}\right\}$ to indicate the current information set in period $t$, according to Engel (1982), if

$$
\mathrm{r}_{t}=\sigma_{t} \xi_{t}
$$

then the process $\left\{r_{t}\right\}$ has an $\operatorname{ARCH}(p)$ characteristic. Here $\sigma$ represents the standard deviation and has the following properties:

$$
\begin{gathered}
E\left(\mathrm{r}_{t} \mid I_{t}\right)=0 \\
\operatorname{Var}\left(\mathrm{r}_{t} \mid I_{t}\right)=\sigma_{t}^{2}=\omega+\sum_{i=1}^{p} \alpha_{i} \xi_{t-i}^{2}
\end{gathered}
$$

On the other hand, for the error term $\xi_{t}$, the following properties must be fulfilled:

$$
\begin{gathered}
E\left(\xi_{t} \mid I_{t}\right)=0 \\
\operatorname{Var}\left(\xi_{t} \mid I_{t}\right)=1
\end{gathered}
$$

In addition, it should be noted that in the above equations, $\omega \geq 0$ and $\alpha_{i} \geq 0$ for all $i=1,2, \ldots$, $q$ (non-negativity condition) (Engle, 1982). Accordingly, the general representation of the $\mathrm{ARCH}(p)$ model is as follows:

$$
\sigma_{t}^{2}=\omega+\sum_{i=1}^{p} \alpha_{i} \xi_{t-i}^{2}
$$

In order to determine the dynamics of conditional variance, sometimes it is necessary to use a high order ARCH model. This makes it necessary to estimate a large number of parameters and therefore the non-negativity condition can be violated. In the generalized ARCH (GARCH) model developed by Bollerslev (1986), lagged values of conditional variance are added to the ARCH model, thereby reducing the number of parameters to be estimated. The general representation of the $\operatorname{GARCH}(p, q)$ model is as follows:

$$
\sigma_{t}^{2}=\omega+\sum_{i=1}^{p} \alpha_{i} \xi_{t-i}^{2}+\sum_{j=1}^{q} \beta_{j} \sigma_{t-j}^{2}
$$

All coefficients in this equation must be positive and the condition $\left(\sum_{i=1}^{p} \alpha_{i}+\sum_{j=1}^{q} \beta_{j}\right)<1$ must be satisfied.

As it can be understood from the non-negativity condition, ARCH and GARCH models are 


\section{Macrothink}

concerned with the magnitude of the volatility and not the direction. Nelson (1991) developed the exponential GARCH (EGARCH) model, which includes the conditional variance that captures the asymmetric response in conditional variance:

$$
\log \left(\sigma_{t}^{2}\right)=\omega+\sum_{i=1}^{p} \alpha_{i}\left|\frac{\xi_{t-i}}{\sqrt{\sigma_{t-i}^{2}}}\right|+\sum_{j=1}^{q} \beta_{j}\left[\log \left(\sigma_{t-j}^{2}\right)\right]+\sum_{k=1}^{r} \gamma_{k} \frac{\xi_{t-k}}{\sqrt{\sigma_{t-k}^{2}}}
$$

In this type of ARCH family, $\alpha$ parameter measures the size or symmetrical effect (GARCH effect) in the model, and the parameter $\beta$ measures the persistence in conditional variance regardless of market conditions. A large value of $\beta$ indicates that the effect of the shock in the market takes a long time to pass. The $\gamma$ parameter measures the asymmetry or leverage effect. If $\gamma=0$ the model is symmetrical. If $\gamma<0$, positive shocks create less volatility than negative shocks, while if $\gamma>0$, positive shocks create more volatility than negative shocks.

\section{Data Analysis and Estimation Results}

In this study, the average overnight repo interest rate realized in the interbank money market will be used to represent the short-term interest rate. The related data was obtained from the Central Bank of the Republic of Turkey (CBRT) through electronic data delivery system. The database used is on a weekly basis and consists of 993 observations covering the period January 2002 - January 2021. The course of the data during the analyzing period can be followed from Figure 1, and the statistical features exhibited in 5-year periods and throughout the period can be seen from Table 2 .

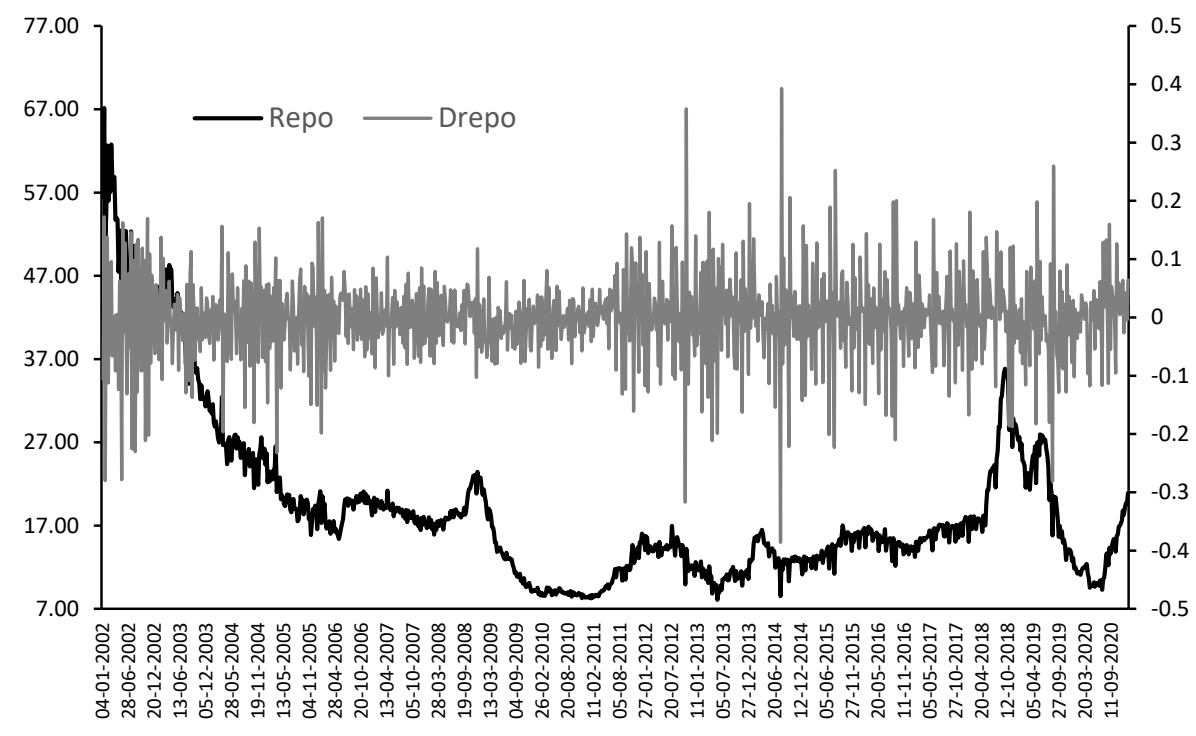

Figure 1. Interbank Repo Rate (Level and Change) in Turkey

Note: Right axis measures the change in repo rate (Drepo) 
Table 2. Summary Statistics of Return Series

\begin{tabular}{|l|l|l|l|l|l|}
\hline & $01 / 04 / 2002$ & $01 / 05 / 2007$ & $01 / 06 / 2012$ & $01 / 06 / 2017$ & $01 / 04 / 2002$ \\
& $12 / 29 / 2006$ & $12 / 30 / 2011$ & $12 / 30 / 2016$ & $01 / 08 / 2021$ & $01 / 08 / 2021$ \\
\hline Mean & -0.004519 & -0.001014 & $-9.38 \mathrm{E}-05$ & 0.001731 & -0.001109 \\
\hline Median & -0.000344 & 0.000000 & 0.003745 & 0.003354 & 0.002131 \\
\hline Maximum & 0.172716 & 0.143228 & 0.392896 & 0.259980 & 0.392896 \\
\hline Minimum & -0.279868 & -0.160995 & -0.385756 & -0.281186 & -0.385756 \\
\hline Std.Dev. & 0.079432 & 0.046863 & 0.090853 & 0.073551 & 0.074409 \\
\hline Skewness & -0.580536 & -0.046365 & 0.034541 & -0.117356 & -0.195671 \\
\hline Kurtosis & 4.081297 & 3.569904 & 6.346397 & 4.532820 & 6.164629 \\
\hline Jarque-Bera & 27.27065 & 3.625613 & 121.8342 & 24.04048 & 420.2785 \\
(Probability) & $(0.000001)$ & $(0.163195)$ & $(0.000000)$ & $(0.000027)$ & $(0.000000)$ \\
\hline Observations & 260 & 261 & 261 & 210 & 992 \\
\hline
\end{tabular}

\subsection{Compliance Analysis}

In order to avoid possible bias and unreasonable convergence, the data should be passed through a compliance analysis before the estimation process. This analysis allows us to select the appropriate model that best describes the data. In this study, the return series (the first difference of logarithmic level series) of repo rate is the raw data. First of all, in order for this time series to be suitable for ARCH modeling, it should be skewed to the right or left, its kurtosis should be sharp and its distribution should not be normal. The values in the last column of Table 1 show that these three features are present in the series considering the whole period. A skewness value less than zero indicates that the series is skewed to the left, a kurtosis value greater than 3 shows that the series exacerbates, and the Jarque - Bera test with zero probability denotes that the series is not normally distributed. Since the return series is considered to be stationary in ARCH family models, the presence of unit root in the time series used should be investigated. The results of the augmented Dickey - Fuller (ADF) and Phillips - Peron (PP) unit root tests carried out for this purpose can be seen in Table 3. In addition to these two tests, the table also includes Dickey-Fuller (Break DF) test, which takes into account the probability of possible break in time series. According to the aforementioned test results, return series regarding the repo rate does not have a unit root and is stationary. Therefore, it is understood that the degree of integration in the used return series is zero, in other words, the series exhibits the I (0) characteristic.

Table 3. Unit Root Test Results

\begin{tabular}{|l|l|l|l|}
\hline Test & Lag & Test Statistic & Probability \\
\hline ADF & $13^{*}$ & 6.060443 & 0.0000 \\
\hline PP & $13^{* *}$ & 54.55801 & 0.0001 \\
\hline Break DF & $0^{*}$ & 52.60146 & 0.0000 \\
\hline * determined by considering Schwarz Information Criterion. \\
** shows the Newey-West band width. \\
\hline
\end{tabular}

Since we have stationary time series it is necessary to examine the autocorrelation and partial autocorrelation functions of the series in order to determine the degree of the ARMA model. 
These functions calculated on the basis of a 52-week lag in order to take into account the long-memory concept are presented in Figure 2.
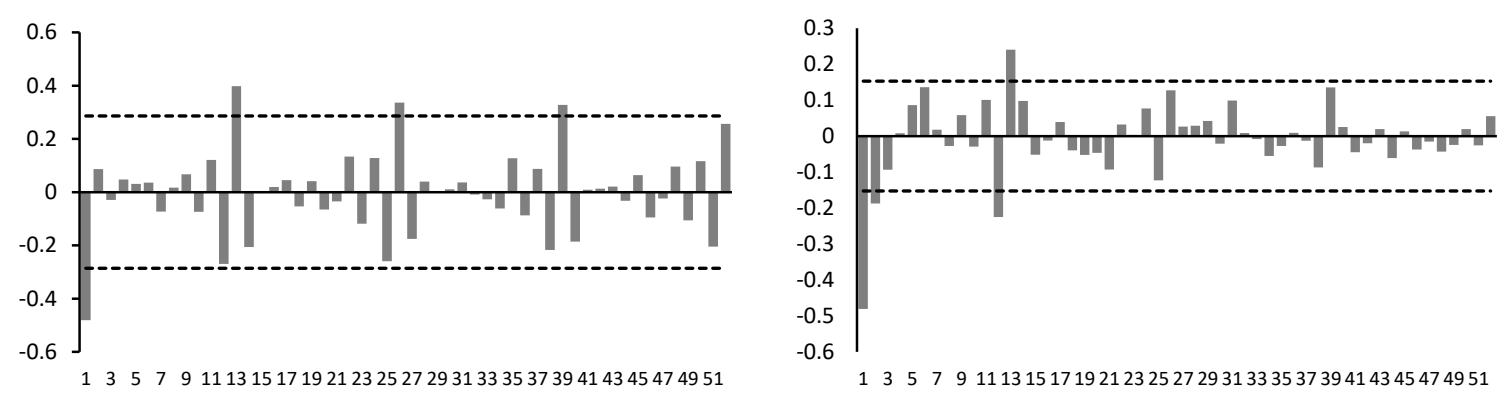

Figure 2. Autocorrelation and Partial Autocorrelation Functions of Return Series

In the examination of the autocorrelation function, it is understood that the autocorrelation values are generally within the standard error bands after the first lag and the presence of a seasonal component in the 12-13th weeks. In the partial autocorrelation function, it is seen that the negative correlation gradually decreases after the first lag and turns into positive. Among the tried alternative ARMA models, the most suitable model is determined as ARMA $(2,2)(13,13)$ according to Akiake Information Criterion. The estimation results of the relevant model are summarized below:

$$
\begin{aligned}
& r_{t}=-0.0028+0.8303 r_{t-1}-0.0778 r_{t-2}-1.3640 \xi_{t-1}+0.5586 \xi_{t-2}+0.8711 \varphi_{t-13}^{r}-0.6213 \\
& \varphi_{t-13}^{\xi} \\
& \begin{array}{llllll}
(0.6910) & (12.205) & (3.3497) & (21.002) & (11.191) & (30.783) \\
{[0,4897]} & {[0.0000]} & {[0.0005]} & {[0.0000]} & {[0.0000]} & {[0.0000]}
\end{array}
\end{aligned}
$$

In the above equation, the values in parentheses below the coefficients indicate absolute $t$ statistics, values in square brackets indicate marginal significance levels. All coefficients except the constant term are statistically significant at the $1 \%$ level. At this stage of the estimation, the autocorrelation should have been removed from the series, but it should be confirmed that the variance effect exists in the series. Autocorrelation and partial autocorrelation functions of residuals obtained from the estimation of ARMA model are given in Figure 3. As can be easily seen from the related functions, autocorrelations are mostly zero and the remainder are pulled into the standard error bands. For ARCH family models to be applicable, the ARCH effect must be present in these residual series. The Engle ARCH test results performed for this purpose are summarized in Table 4. 

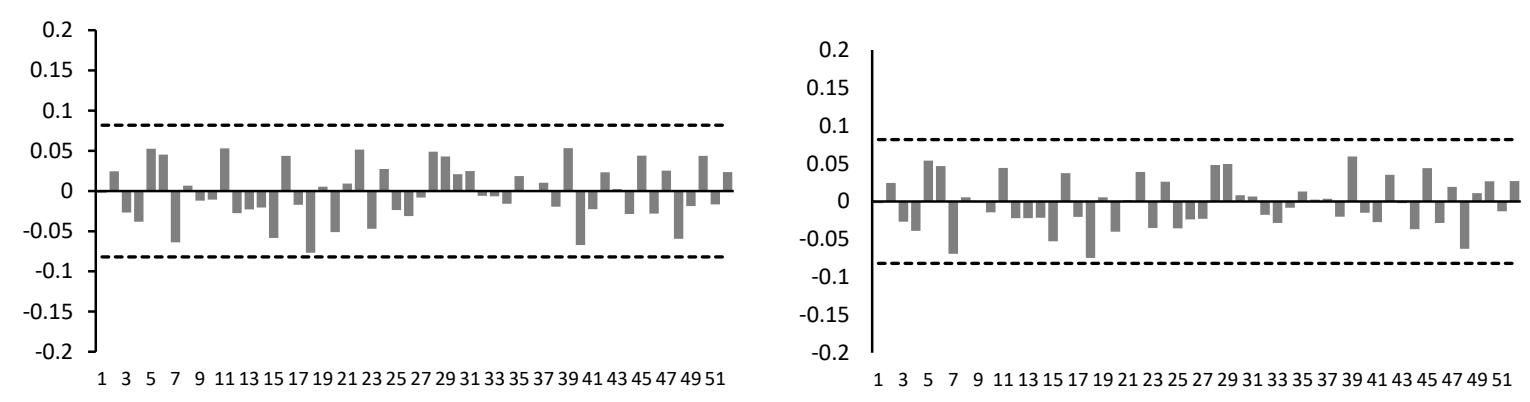

Figure 3. Autocorrelation and Partial Autocorrelation Functions of Residuals

Table 4. Engle ARCH Test for Residuals

\begin{tabular}{|l|l|l|l|l|}
\hline Lag & F Test & Probablity & Obs* $^{2}$ & Probability $\left(\chi^{2}\right)$ \\
\hline 1 & 12.2796 & 0.0005 & 12.1473 & 0.0005 \\
\hline 2 & 6.0977 & 0.0023 & 12.0777 & 0.0024 \\
\hline 3 & 5.0745 & 0.0017 & 15.0442 & 0.0018 \\
\hline 4 & 3.904 & 0.0038 & 15.4430 & 0.0039 \\
\hline 9 & 2.6726 & 0.0046 & 23.6980 & 0.0048 \\
\hline 12 & 2.1194 & 0.0138 & 25.0978 & 0.0144 \\
\hline 24 & 1.7808 & 00121 & 41.9312 & 0.0131 \\
\hline 36 & 1.5975 & 0.0151 & 56.2399 & 1.0170 \\
\hline 50 & 1.4253 & 0.0305 & 69.6849 & 0.0342 \\
\hline
\end{tabular}

It appears that the residual terms obtained are not independent of the $\mathrm{ARCH}$ effect, but the longer the lag number, the weaker the effect. Note that the increase in probability values becomes evident after the third lag. For this reason, it would be appropriate to estimate the ARCH family models for the 1st, 2nd and 3rd order.

\subsection{Estimation of ARCH Models}

Models that should be estimated according to Engle ARCH test results are ARCH ((1), (2) and (3)], GARCH $((1,1),(1,2),(1,3),(2,1),(2,2),(2,3),(3,1),(3,2)$ and $(3,3)]$ and EGARCH $((1,1),(1,2),(1,3),(2,1),(2,2),(2,3),(3,1),(3,2)$ and $(3,3)]$. In order to decide which of these models is the most appropriate estimator, we should estimate each alternative model and prefer the model that generates the minimum value of information criteria (Akiake, Schwarz and Hannan - Quin). Table 5 shows a summary of the information criteria from the estimated alternative models. 


\section{Macrothink}

Business and Economic Research

ISSN 2162-4860

2021, Vol. 11, No. 1

Table 5. Information Criteria for Alternative Models

\begin{tabular}{|l|l|l|l|}
\hline Model & Akiake & Schwarz & Hannan-Quin \\
\hline ARCH (1) & $\mathbf{2 . 4 7 0 4 3 9}$ & $\mathbf{2 . 4 6 0 1 7 2}$ & $\mathbf{2 . 4 6 6 5 2 6}$ \\
\hline ARCH $(2)$ & 2.471562 & 2.466162 & 2.466693 \\
\hline ARCH $(3)$ & 2.486605 & 2.466070 & 2.478779 \\
\hline GARCH (1,1) & $\mathbf{2 . 4 8 5 5 3 0}$ & $\mathbf{2 . 4 7 0 1 7 9}$ & $\mathbf{2 . 4 7 9 6 6 0}$ \\
\hline GARCH $(1,2)$ & 2.525715 & 2.505181 & 2.517889 \\
\hline GARCH $(1,3)$ & 2.536929 & 2.511262 & 2.527147 \\
\hline GARCH $(2,1)$ & 2.534017 & 2.513483 & 2.526191 \\
\hline GARCH $(2,2)$ & 2.542480 & 2.516812 & 2.532698 \\
\hline GARCH $(2,3)$ & 2.544218 & 2.513417 & 2.532480 \\
\hline GARCH $(3,1)$ & 2.533954 & 2.508287 & 2.524172 \\
\hline GARCH $(3,2)$ & 2.544415 & 2.513613 & 2.532676 \\
\hline GARCH $(3,3)$ & 2.542701 & 2.506766 & 2.529006 \\
\hline EGARCH $(1,1)$ & 2.487025 & 2.466491 & 2.479199 \\
\hline EGARCH $(1,2)$ & 2.531029 & 2.505361 & 2.521547 \\
\hline EGARCH $(1,3)$ & 2.524916 & 2.512115 & 2.531177 \\
\hline EGARCH (2,1) & $\mathbf{2 . 4 8 4 9 0 9}$ & $\mathbf{2 . 4 5 9 2 4 2}$ & $\mathbf{2 . 4 7 5 1 2 7}$ \\
\hline EGARCH $(2,2)$ & 2.549579 & 2.518777 & 2.537840 \\
\hline EGARCH $(2,3)$ & 2.548169 & 2.512234 & 2.534447 \\
\hline EGARCH $(3,1)$ & 2.550308 & 2.519507 & 2.538669 \\
\hline EGARCH $(3,2)$ & 2.548207 & 2.512272 & 2.534512 \\
\hline EGARCH $(3,3)$ & 2.543780 & 2.502712 & 2.528128 \\
\hline
\end{tabular}

Note: Highlighted models produce the minimum information criteria in each alternative.

According to the information criteria in the table, ARCH (1), GARCH $(1,1)$ and EGARCH $(2,1)$ models are determined as the most consistent estimators. The results obtained by estimating these models are as follows:

$\mathrm{ARCH}(1)$ :

$$
\begin{aligned}
\sigma_{t}^{2}= & 0.0037+0.3281 \xi_{t-1}^{2} \\
& (26.597) \\
& (5.8365) \\
{[0.0000] } & {[0.0000] }
\end{aligned}
$$

$\operatorname{GARCH}(1,1)$ :

$$
\begin{aligned}
& \sigma_{t}^{2}=0.0002+0.1122 \xi_{t-1}^{2}+0.8639 \sigma_{t-1}^{2} \\
& \text { (3.2294) (7.5527) (50.719) } \\
& {[0.0012] \quad[0.0000] \quad[0.0000]}
\end{aligned}
$$

$\operatorname{EGARCH}(2,1)$ : 


$$
\begin{gathered}
\log \left(\sigma_{t}^{2}\right)=-0.0453+0.2356\left|\frac{\xi_{t-1}}{\sqrt{\sigma_{t-1}^{2}}}\right|+0.1661\left|\frac{\xi_{t-2}}{\sqrt{\sigma_{t-2}^{2}}}\right|+0.8015 \log \left(\sigma_{t-1}^{2}\right)+0.0331 \frac{\xi_{t-1}}{\sqrt{\sigma_{t-1}^{2}}} \\
\left.\begin{array}{cccc}
(3.0268)(3.6298) & (2.5308) & (3.1100)
\end{array}\right]
\end{gathered}
$$

In the above equations, the values in parentheses below the coefficients indicate absolute $z$ statistics, while the values in square brackets indicate marginal significance levels. All of the coefficients in all three models estimated are statistically significant at the $1 \%$ level. On the other hand, in ARCH and GARCH models, the condition that the coefficients are not negative, and in the GARCH model, the total of behavioral coefficients are less than one are fulfilled. As Table 6 below indicates, ARCH (1), GARCH $(1,1)$ and EGARCH $(2,1)$ models used as consistent models are independent of autocorrelation (Ljung - Box tests) and heteroscedasticity (Engle ARCH tests) problems. As a result, the $\mathrm{ARCH}$ family models, which are determined as the most consistent models of volatility, have produced statistically significant results and can therefore be used for in-sample and out-of-sample forecasting of the short-term interest rate. Which of these models has the best performance will be the subject of the next section.

Table 6. Residuals Diagnostic Tests

\begin{tabular}{|l|l|l|l|l|l|l|l|l|}
\hline Test & \multirow{2}{*}{ Distr. } & Lag & \multicolumn{2}{|l|}{ ARCH(1) } & \multicolumn{2}{l|}{ GARCH (1,1) } & \multicolumn{2}{|l|}{ EARCH (2,1) } \\
\cline { 4 - 9 } & & & Stat. & Prob & Stat. & Prob. & Stat. & Prob. \\
\hline Ljung-Box & $\chi^{2}$ & 24 & 24.923 & 0.410 & 19.120 & 0.724 & 26.621 & 0.322 \\
\hline Ljung-Box & $\chi^{2}$ & 36 & 42.467 & 0.212 & 34.120 & 0.558 & 43.853 & 0.173 \\
\hline Ljung-Box & $\chi^{2}$ & 50 & 60.281 & 0.151 & 48.891 & 0.518 & 58.069 & 0.202 \\
\hline ARCH & $F$ & 1 & 0.103 & 0.749 & 2.064 & 0.152 & 8.328 & 0.004 \\
\hline ARCH & $\chi^{2}$ & 1 & 0.103 & 0.749 & 2.064 & 0.151 & 8.272 & 0.004 \\
\hline
\end{tabular}

\section{Forecasting Short-term Interest Rate}

In this section, the best estimator will be determined by evaluating the in-sample forecasting performance of previously developed models, and within this framework, out-of-sample estimation will be discussed. Table 7 shows the RMSE, MAE, Theil U1 and Theil U2 criteria for evaluating the consistency of the in-sample forecasts.

Table 7. Criteria for Assessing Forecast Errors

\begin{tabular}{|l|l|l|l|}
\hline Criterion & $A R C H(1)$ & $G A R C H(1,1)$ & $\operatorname{EGARCH}(2,1)$ \\
\hline Root mean squared error & 1.170806 & $\mathbf{1 . 1 7 0 6 4 9}$ & 1.178616 \\
\hline Mean absolute error & 0.796106 & $\mathbf{0 . 7 9 5 1 1 8}$ & 0.795691 \\
\hline Theil U1Coefficient & 0.027601 & 0.0275790 & 0.027637 \\
$\quad$ (Bias proportion) & $(0.000131)$ & $(0.000147)$ & $(0.000020)$ \\
$\quad$ (Variance proportion) & $(0.000017)$ & $(0.000102)$ & $(0.000039)$ \\
(Covariance proportion) & $(0.999852)$ & $(0.999751)$ & $(0.999941)$ \\
\hline Theil U2 Coefficient & 0.758518 & 0.754626 & 0.755269 \\
\hline
\end{tabular}




\section{Macrothink}

Among the criteria in the table, RMSE and MAE criteria make sense by comparison. When the same time series is estimated with different models, it is understood that the model that produces the lowest RMSE and MAE value performs better in forecasting the same time series. Note that both criteria indicate that the GARCH $(1,1)$ model is more successful in this sense. Theil coefficients are used to evaluate the forecasting performance of a model. The Theil U1 coefficient varies between 0 and 1, and a coefficient of 0 indicates that the predicted and actual values are identical (the forecast error is zero). Therefore, the closer the coefficient to zero is obtained, the more successful the prediction is. The percentage distributions in parentheses below the coefficient show how much of the current error is due to bias, variance and covariance, respectively. As long as the larger part of the current error is due to covariance, the predictive power of the model and the ability to catch the turning points in the series will be high. All three models discussed show a very strong performance in this sense. The last criterion in the table is Theil U2 coefficient. Although the lower limit of the U2 coefficient is zero, it does not have an upper limit. A coefficient equal to zero indicates $\widehat{Y}_{t}=Y_{t}$ while a coefficient equal to one shows $\widehat{Y}_{t}=Y_{t-1}$. For this reason, a U2 coefficient less than 1 indicates that the model has an adequate performance. According to the table, all three models are sufficient in this sense. Among the models developed in the light of these evaluations, it is understood that the GARCH $(1,1)$ model produces consistent and sufficient estimates and has the best modelling strength the variability in the analyzed time series. Figure 4 below shows the in-sample repo rate forecasts obtained through the GARCH $(1,1)$ model. Part A of the figure shows the predicted repo rates for the full sample and while part B indicates the predictions for the last 24 months. It is seen that the GARCH $(1,1)$ model produces forecasts close to the actual interest rate and has a strong performance in catching up and down turning points observed in the interest rate.

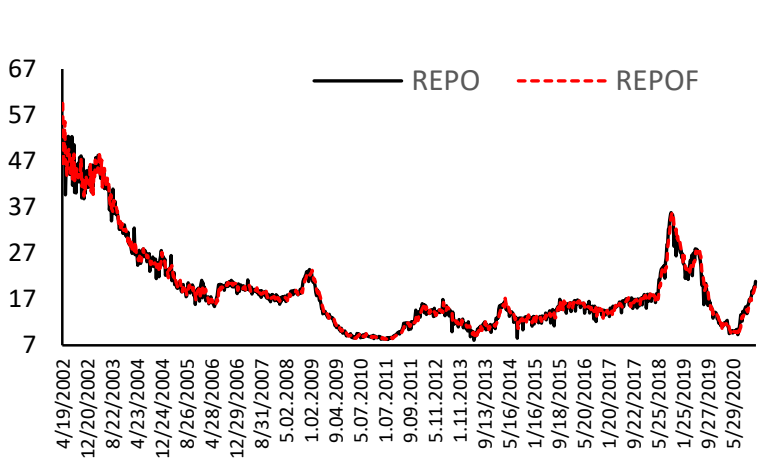

(A) Full Sample

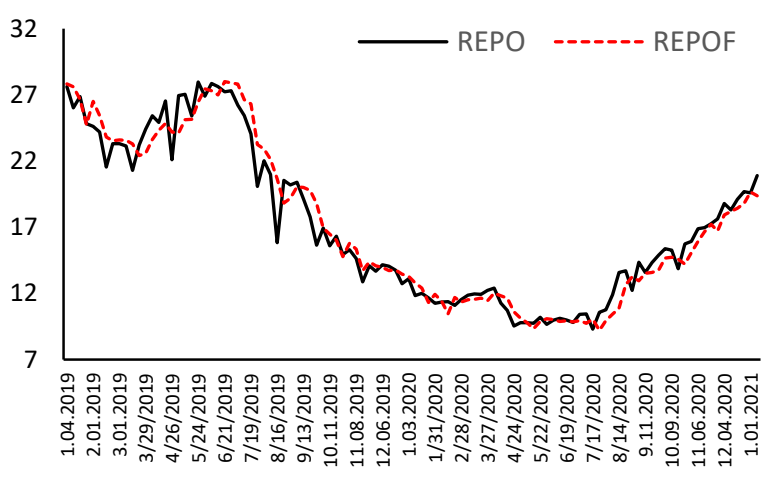

(B) Last 24 Months

Figure 4. Forecasted and Actual Repo Rates

After determining the best estimator based on the in-sample estimation performance, the out-of-sample forecast can be performed as the ultimate goal of this study. The out-of-sample forecast includes prediction of repo rate for the next 6-month at weekly frequency. While forecast results are given visually in Figure 5 with \pm 2 standard error bands, Table 8 summarizes the same results numerically. Results show that at the end of the forecast period, 


\section{Macrothink}

i.e. end of June 2021, forecasted repo rate for Turkish interbank market is $21.92 \%$.

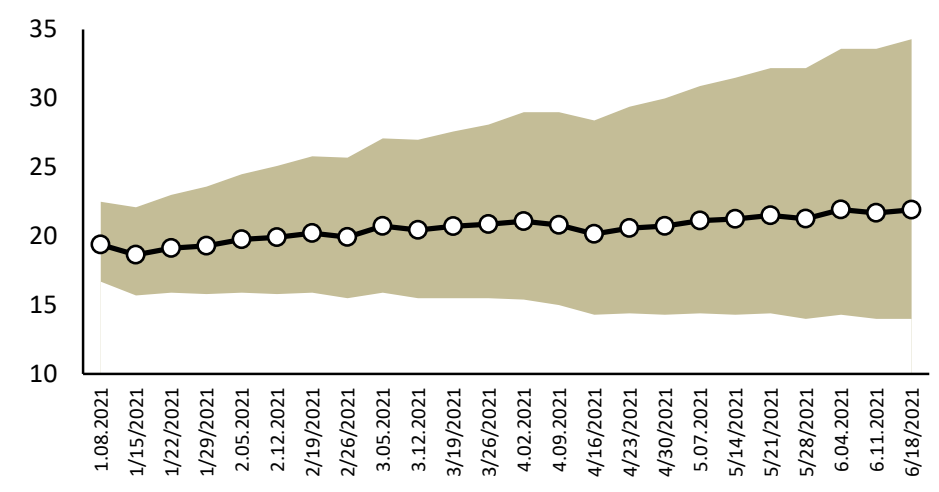

Figure 5. Out-of-Sample Forecasts

Table 8. Out-of-Sample Forecasts

\begin{tabular}{|l|l|l|l|l|l|l|l|}
\hline Date & -2 SE & Point Forecast & +2 SE & Date & -2 SE & Point Forecast & +2 SE \\
\hline $1 / 08 / 2021$ & 16.7 & 19.39 & 22.5 & $4 / 02 / 2021$ & 15.4 & 21.09 & 29.0 \\
\hline $1 / 15 / 2021$ & 15.7 & 18.64 & 22.1 & $4 / 09 / 2021$ & 15.0 & 20.81 & 29.0 \\
\hline $1 / 22 / 2021$ & 15.9 & 19.13 & 23.0 & $4 / 16 / 2021$ & 14.3 & 20.17 & 28.4 \\
\hline $1 / 29 / 2021$ & 15.8 & 19.30 & 23.6 & $4 / 23 / 2021$ & 14.4 & 20.58 & 29.4 \\
\hline $2 / 05 / 2021$ & 15.9 & 19.76 & 24.5 & $4 / 30 / 2021$ & 14.3 & 20.73 & 30.0 \\
\hline $2 / 12 / 2021$ & 15.8 & 19.92 & 25.1 & $5 / 07 / 2021$ & 14.4 & 21.12 & 30.9 \\
\hline $2 / 19 / 2021$ & 15.9 & 20.22 & 25.8 & $5 / 14 / 2021$ & 14.3 & 21.26 & 31.5 \\
\hline $2 / 26 / 2021$ & 15.5 & 19.94 & 25.7 & $5 / 21 / 2021$ & 14.4 & 21.51 & 32.2 \\
\hline $3 / 05 / 2021$ & 15.9 & 20.74 & 27.1 & $5 / 28 / 2021$ & 14.0 & 21.26 & 32.2 \\
\hline $3 / 12 / 2021$ & 15.5 & 20.45 & 27.0 & $6 / 04 / 2021$ & 14.3 & 21.94 & 33.6 \\
\hline $3 / 19 / 2021$ & 15.5 & 20.73 & 27.6 & $6 / 11 / 2021$ & 14.0 & 21.69 & 33.6 \\
\hline $3 / 26 / 2021$ & 15.5 & 20.87 & 28.1 & $6 / 18 / 2021$ & 14.0 & 21.92 & 34.3 \\
\hline
\end{tabular}

\section{Conclusion}

During the global financial crisis of 2008-2009, the level and variability of interest rates fluctuated significantly. This situation has led investors to better understand the importance of interest rate volatility in financial market analysis. Volatility of interest rates is important not only for the return of the portfolio, but also for the investment decision. On the other hand, since monetary policy is carried out through short-term interest rates that determine the long-term rates, it is extremely important for central banks to analyze short-term interest rate variability. The interest rate is the cornerstone of many financial models. The mentioned high volatility in interest rates during the financial crisis of 2008/2009 caused to increase uncertainty in the markets. This has led many researchers to focus on analyzing and modeling the dynamics of changes in short-term interest rates. This study aims to analyze the volatility in short-term interest rates in Turkey by considering the interbank repo rate and to forecast it for the next 6-month period at weekly frequency. 
Volatility calibrates the variation in interest rates relative to the anticipated average interest rate. As long as we calculate risk as a deviation from expected return, the volatility in interest rates is intended to explain the indeterminacy that causes high risk in money markets. Thus, movements in short-term interest rates are determined by a large set of factors (like financial, political and global factors). The estimation of interest rate volatility is the determination of the uncertainty covering the expectations of the market (especially related to the future course of monetary policy interest rates). Although different techniques are used for modeling volatility in the literature, the most commonly used method is ARCH family models. In this study, ARCH, GARCH and EGARCH models have been preferred for this purpose.

Above mentioned time series models have used to evaluate the volatility of interbank repo rate series obtained from Turkey. Using weekly frequency data for the period January 2002 January 2021, it is aimed to determine the model that best describes the stochastic volatility in the data. All of the different preference criteria point to the ARCH (1), GARCH $(1,1)$, and EGARCH $(1,1)$ models as the most appropriate model. However, after parameter estimates, as a result of a series of diagnostic and goodness of fit tests, it has been determined that the GARCH $(1,1)$ model produces the most satisfactory results. The in-sample repo forecasts obtained by using this preferred model are very close to actual interest rates and are quite successful in determining turning points. As a result of the in-sample estimates that were found to be sufficient, interest rate forecasts for the next 6 months were realized and the repo interest rate for the end of June 2021 was estimated at 21.92 percent.

\section{References}

Ariff, M., \& Sarkar, S. (2002). The effect of interest rate volatility on treasury yields. Applied Financial Economics, 12, 667-672. https://doi.org/10.1080/09603100010018759

Bali, T. G. (2000). Testing the empirical performance of stochastic volatility models of the short-term interest rate. Journal of Financial and Quantitative Analysis, 35, 191-215. https://doi.org/10.2307/2676190

Bali, T. G., \& Wu, L. (2006). A comprehensive analysis of the short-term interest-rate dynamics. Journal of Banking and Finance, 30, 1269-1290.

https://doi.org/10.1016/j.jbankfin.2005.05.003

Bauer, M. D., \& Mertens, T. M. (2018). Economic forecasts with the yield curve. Research from Federal ReserveBank of San Francisco. FRBSF Economic Letter.

Bayraci, S., \& Unal, G. (2018). Stochastic interest rate volatility modeling with a continuous-time GARCH $(1,1)$ model. Journal of Computational and Applied Mathematics, 259, 464-473. https://doi.org/10.1016/j.cam.2013.10.017

Bean, M. A. (2016). Determinants of interest rates. Society of Actuaries Financial Mathematics Study Note, FM-26-17.

Boscher, H., Fronk, E. M., \& Pigeot, I. (2000). Forecasting interest rates volatilities by GARCH $(1,1)$ and stochastic volatility models. Statistical Papers, 41, 409-422.

https://doi.org/10.1007/BF02925760 


\section{Macrothink

Bollerslev, T. (1986). Generalized autoregressive conditional heteroscedasticity. Journal of Econometrics, 31, 307-327. https://doi.org/10.1016/0304-4076(86)90063-1

Brousseau, V., \& Durre, A. (2013). Interest rate volatility a consol rate-based measure. European Central Bank Working Paper Series, 1505.

Chiarella, C., He, X. Z., \& Nikitopoulos, C. S. (2015). Modelling interest rate dynamics in derivative security pricing. Dynamic Modelling and Econometrics in Economics and Finance, 21, 439-467. https://doi.org/10.1007/978-3-662-45906-5_22

Christiansen, C. (2005). Multivariate term structure models with level and heteroscedasticity effects. Journal of Banking and Finance, 29, 1037-1057.

https://doi.org/10.1016/j.jbankfin.2003.11.004

Dabale, W. P., \& Jagero, N. (2013). Causes of interest rate volatility and its economic implications in Nigeria. International Journal of Academic Research in Accounting, Finance and Management Sciences, 4, 27-32. http://dx.doi.org/10.6007/IJARAFMS/v3-i4/304

Dayioglu, T. (2012). Forecasting overnight interest rates volatility with symmetric GARCH models. Journal of Applied Finance and Banking, 2, 151-162.

Diaz, A., Jareno, F., \& Navarro, E. (2010). A principal component analysis of the Spanish volatility term structure. International Research Journal of Finance and Economic Issues, 49, 150-155.

Dube, S., \& Zhou, Y. (2013). South Africa's short and long term interest rates: a threshold cointegration analysis. Business and Economic Research, 3, 187-211.

https://doi.org/10.5296/ber.v3i1.3121

Edwards, S., \& Susmel, R. (2003). Interest-rate volatility in emerging markets. Review of Economics and Statistics, 85, 328-348. https://doi.org/10.1162/003465303765299855

Engle, R. F. (1982). Autoregressive conditional heteroscedasticity with estimates of the variance of United Kingdom inflation. Econometrica, 50, 987-1007.

https://doi.org/10.2307/1912773

Engle, R. (2001). Garch 101: An introduction to the use of ARCH/GARCH models in applied econometrics. Social Science Electronic Publishing. https://doi.org/10.1257/jep.15.4.157

Floros, C. (2008). Modelling volatility using GARCH models: evidence from Egypt and Israel. Middle Eastern Finance and Economics, 2, 31-41.

Hassani, H., Yeganegi, M. R., Cunado, J., \& Gupta, R. (2019). Forecasting interest rate volatility of the United Kingdom: evidence from over 150 years of data, Journal of Applied Statistics, 20, 1-16. https://doi.org/10.1080/02664763.2019.1666093

Hegerty, S. W. (2011). Interest-rate volatility and volatility spillovers in emerging Europe. International Review of Applied Economics, 25, 599-614.

https://doi.org/10.1080/02692171.2011.557049 


\section{Macrothink}

Business and Economic Research ISSN 2162-4860 2021, Vol. 11, No. 1

Hegerty, S. W. (2014). Interest-rate volatility and volatility transmission in nine Latin American countries. Applied Financial Economics, 24, 927-937.

https://doi.org/10.1080/09603107.2014.916387

Hong, Y., Lin, H., \& Wang, S. (2010). Modeling the dynamics of Chinese spot interest rates. Journal of Banking and Finance, 34, 1047-1061.

https://doi.org/10.1016/j.jbankfin.2009.11.002

Hong, H., Chen, N., O’Brien, F., \& Ryan, J. (2018). Stock return predictability and model instability: evidence from mainland China and Hong Kong. The Quarterly Review of Economics and Finance, 68, 132-142. https://doi.org/10.1016/j.qref.2017.11.007

Hou, A. J., \& Suardi, S. (2011). Modelling and forecasting short-term interest rate volatility: a semiparametric approach. Journal of Empirical Finance, 18, 692-710.

https://doi.org/10.1016/j.jempfin.2011.05.001

Irfan, M., Irfan M., \& Awais, M. (2010a). Modeling conditional heteroscedasticity and forecasting in short term interest rate of KIBOR. International Journal of Economic Perspectives, 4, 635-654.

Irfan, M., Irfan, M., \& Awais, M. (2010b). Modeling volatility of short term interest rates by ARCH family models: evidence from Pakistan and India. World Applied Sciences Journal, 9, 1089-1094.

Joslin, S., \& Konchitchki, Y. (2018). Interest rate volatility, the yield curve, and the macro economy. Journal of Financial Economics, 128, 344-362.

https://doi.org/10.11648/j.ijber.20190803.11

Koutmos, G. (2012). Modeling interest rate volatility: an extended EGARCH approach. Managerial Finance, 38, 628-635. https://doi.org/10.1108/03074351211226265

Leon, K. (2008). The effect of interest rates volatility on stocks return and volatility: evidence from Korea. International Research Journal of Financial Economics, 14, 1450-1487.

Li, S., Abubakar, M., Ain, Q., \& Yousaf, T. (2019). Modelling short term interest rate volatility with time series model: a case of Pakistani financial markets. In Janusz Kacprzyk (Ed.), Proceedings of the thirteenth international conference on management science and engineering management (pp.496-506). Springer.

https://doi.org/10.1007/978-3-030-21248-3_36

Malik, F. J., \& Nishat, M. (2017). Real interest rate volatility in the Pakistani economy: a regime switching approach. Business Review, 12, 22-32.

Maranga, C. K., Mwangi, M., \& Kaijage, E. (2018). Dynamics of the term structure of interest rates: a critical literature review. Journal of Economics and Finance, 9, 45-50. https://doi.org/10.9790/5933-090104550

Nelson, D. B. (1991). Conditional heteroscedasticity in asset returns: a new approach. Econometrica, 59, 347-370. https://doi.org/10.2307/2938260 


\section{Macrothink}

Business and Economic Research ISSN 2162-4860 2021, Vol. 11, No. 1

Neupane, S. (2011). Examining volatility of interbank rate in Nepal. Economic Review, 23, 37-53.

Olan, T. H., \& Sandy, S. (2005). Testing for asymmetry in interest rate volatility in the presence of a neglected level effect. University of Melbourne Department of Economics Working Paper 945.

Olweny, T. (2011). Modelling volatility of short-term interest rates in Kenya. International Journal of Business and Social Science, 2, 289-303.

Smith, D. R. (2002). Markov-switching and stochastic volatility diffusion models of short term interest rates. Journal of Business and Economic Statistics, 20, 183-197.

https://doi.org/10.1198/073500102317351949

Sundaresan, S. (2009). Fixed income markets and their derivatives (3rd ed.). Elsevier.

Takamizawa, H. (2015). Predicting interest rate volatility using information on the yield curve. International Review of Finance, 15, 347-386. https://doi.org/10.1111/irfi.12053

Tian, S., \& Hamori, S. (2015). Modeling interest rate volatility: a realized GARCH approach. Journal of Banking and Finance, 61, 158-171.

https://doi.org/10.1016/j.jbankfin.2015.09.008

van der Merwe, E., Mollentze, S., Rossouw, J. J., \& Leshoro, L. A. (2014). Monetary policy in South Africa (2nd ed.). Oxford University Press.

\section{Copyright Disclaimer}

Copyright for this article is retained by the author(s), with first publication rights granted to the journal.

This is an open-access article distributed under the terms and conditions of the Creative Commons Attribution license (http://creativecommons.org/licenses/by/4.0/). 